Original Research Paper

\title{
Changes in the Rumen Papillae During the Periparturient Transition in Holstein Dairy Cows are Accompanied by Changes in Abundance of Proteins Involved in Intracellular pH Regulation, But not SCFA Transport
}

\author{
${ }^{1}$ Anne Hermen Laarman, ${ }^{1}$ Adam Kleinberg, ${ }^{2}$ Michael Alexander Steele, \\ ${ }^{1}$ Ousama AlZahal and ${ }^{1}$ Brian William McBride \\ ${ }^{I}$ Department of Animal and Poultry Science, University of Guelph, Guelph, Canada \\ ${ }^{2}$ Department of Animal, Food and Nutritional Science, University of Alberta, Edmonton, Canada
}

\author{
Article history \\ Received: $27-2-2015$ \\ Revised: 4-3-2015 \\ Accepted: 18-4-2015 \\ Corresponding Author: \\ Anne Hermen Laarman \\ Department of Animal and \\ Poultry Science ANNU \\ (Building 70), University of \\ Guelph 50 Stone Rd E Guelph, \\ Canada N1G 2W1 \\ Tel: +1 5198244120 ext \\ 58353 \\ Email: anne.laarman@ualberta.net
}

\begin{abstract}
The objective of this study was to examine changes in SCFA transport capacity in the rumen epithelium during the parturition transition period. Twelve pregnant, cannulated primiparous and multiparous cows were fed a standard Total Mixed Ration (TMR) for the duration of the dry period; after calving, all cows were switched to an early lactation TMR. Rumen $\mathrm{pH}$, fluid and biopsies were taken 3 weeks before anticipated calving (PRE), 1 week after actual calving (PERI) and 6 weeks after calving (POST). Rumen biopsies were analyzed for transport protein abundance using immunofluorescence. Immunofluorescence analysis showed no significant changes in the abundance of monocarboxylate cotransporter, isoform 1 among the PRE, PERI and POST periods $(16878 \pm 1555$ A.U., $15613 \pm 1508$ A.U. and $16886 \pm 1555$ A.U. respectively; MCT1). Also, sodium/proton exchanger, isoform 3 (NHE3) was not significantly different among the PRE, PERI and POST periods (10467 \pm 1066 A.U., $9465 \pm 1066$ A.U., $8552 \pm 1109$ A.U., respectively). Sodium/Bicarbonate Co-transporter, isoform 1 ( $\mathrm{NBC1}$ ) was likewise unaffected by time, with the protein abundance among PRE, PERI and POST parturition periods changing from $16467 \pm 1274$ A.U., $13983 \pm 1318$ A.U. and $15047 \pm 1324$ A.U., respectively. Abundance of Carbonic Anhydrase, isoform 2 (CA2) decreased from $12332 \pm 1580$ A.U (PRE) to $7235 \pm 1580$ (PERI) and $8121 \pm 1643$ (POST) and this decrease was significant $(p=0.01$ PRE v. PERI). The observed changes in protein abundance suggest that long-term adaptation of the rumen epithelium occurs to increase transport capacity. Decreased CA2 abundance suggests that intracellular acidification is occurring as part of epithelial remodelling. Taken together, this implies that, during the periparturient transition, a decrease in rumen $\mathrm{pH}$ leads to a decrease in intracellular $\mathrm{pH}$ in the rumen epithelium, promoting epithelial remodelling that result in increased SCFA transport capacity.
\end{abstract}

Keywords: Rumen Epithelium, Periparturient Transition, Transport Capacity, Epithelial Remodelling

\section{Introduction}

The transition period in dairy cows, the time surrounding parturition, is marked by large dietary changes. Prior to parturition, dairy cows in North America are typically fed a high forage, low energy diet, aimed at avoiding excessive build-up of non-esterified fatty acid reserves, which can cause adverse health events after calving (Drackley, 1999). After calving, dairy cows are typically fed high energy, rapidly fermentable diets that substantially increase ruminal fermentation due to greater dry matter intake (Reynolds et al., 2004). Increased ruminal fermentation places greater demand on absorption of Short Chain Fatty Acids (SCFA) across the 
rumen epithelium, resulting in morphological adaptations in the rumen wall. High energy diets have been documented by an increase in papillae length, width and surface area in the rumen of goats (Shen et al., 2004). The adaptation process results in major proliferation of the rumen epithelium, the integrity of which is important in preventing ruminal bacteria from entering the bloodstream (Plaizier et al., 2008). Thus, the transition period and its encompassing dietary and physiological changes put tremendous adaptive pressure on the rumen epithelium.

Structurally, the rumen epithelium is organized into four distinct strata: The stratum corneum, stratum granulosum, stratum spinosum and stratum basale (Graham and Simmons, 2005). Previous studies have confirmed that most of the metabolic activity and most of the transporters are located in the strata spinosum and basale (Graham and Simmons, 2005). One of the major transporters on the basolateral membrane are Monocarboxylate Cotransporter isoform 1 (MCT1; Graham et al., 2007) and Sodium/Bicarbonate Cotransporter isoform 1 (NBC1; Connor et al., 2010). On the apical side of the epithelium are several transport proteins, such as Anion Exchanger isoform 2 (AE2), putative anion transporter, sodium/proton exchanger isoform 3 (NHE3) and monocarboxylate co-transporter 4 (MCT4; Connor et al., 2010). Together, these transport proteins are responsible for the facilitated uptake of SCFAs. Alongside this facilitated SCFA uptake is passive diffusion of associated SCFAs. Since the nonacidotic, optimal $\mathrm{pH}$ of the rumen is between 1 to $2 \mathrm{pH}$ units above the SCFAs' $\mathrm{pK}_{\mathrm{a}}$ value of 4.7 (AlZahal et al., 2007), approximately $90-99 \%$ of SCFAs in the rumen exist in the dissociated state. The total uptake of SCFAs from the rumen into the epithelial cells depends on both passive diffusion and facilitated uptake mechanisms (Aschenbach et al., 2009).

Once inside the epithelial cells, the SCFA exists almost purely in the dissociated form, due to a cellular $\mathrm{pH}$ of 7.4. Acidotic challenges to the intracellular $\mathrm{pH}$ result in a rapid recovery that aims to restore $\mathrm{pH}$ homeostasis in the cell within $10 \mathrm{~min}$ (Müller et al., 2000). Several mechanisms exist to regulate intracellular $\mathrm{pH}$; prominent intracellular $\mathrm{pH}$-regulating include sodium proton exchangers (Kiela et al., 2003: Müller et al., 2000), which export protons from the cytosol and Carbonic Anhydrase isoform 2 (CA2), which reversibly catalyzes the carbon dioxide/bicarbonate equilibrium in the cytosol, thereby eliminating protons from the cytosol. Further, CA2 has been found to be integral to the transport of AE1, with AE1 and several other transport proteins like downregulated in adenoma, containing a CA2attachment site in their carboxy-terminus (Sterling et al., 2001). Further, MCT activity is enhanced by physically binding with CA2 (Klier et al., 2014). This highlights how SCFA transport mechanisms are very much intertwined with intracellular $\mathrm{pH} \quad\left(\mathrm{pH}_{\mathrm{i}}\right)$-regulation mechanisms, thus the study of SCFA transport naturally includes $\mathrm{pH}_{\mathrm{i}}$ regulation.

Currently, our understanding of the adaptability of the rumen epithelium to dietary changes remains limited. While our understanding of morphological changes are well-established, the molecular changes on SCFA transport capacity are less understood. The objective of this study was to study changes in protein abundance of important SCFA-transporters in the rumen epithelium as well as proteins involved in $\mathrm{pH}_{\mathrm{i}}$ regulation, focusing specifically on the transition period. The hypothesis was that the increase in diet fermentability would cause increases in SCFA transporters and modulate the abundance of proteins involved in $\mathrm{pH}_{\mathrm{i}}$ regulation.

\section{Materials and Methods}

\section{Husbandry and Sampling}

This experiment was approved by the Animal Care Committee of the University of Guelph under the guidelines of the Canadian Council of Animal Care (Ottawa, ON) and is a partner study using the same animals as Dionissopoulos et al. (2014). Twelve cannulated primiparous (mean wt. $644 \pm 13 \mathrm{~kg}$ ) and multiparous (mean wt. $760 \pm 10 \mathrm{~kg}$ ) Holstein cows were selected for this study; one was removed for health reasons (Dionissopoulos et al., 2014). All cows were fed a standard dry-cow ration with $46.0 \%$ Neutral Detergent Fiber (NDF) and 34.0\% Non-Fiber Carbohydrates (NFC) before parturition; immediately following parturition, all cows were fed an early lactation TMR with $34.0 \% \mathrm{NDF}$ and $43.0 \%$ NFC (Dionissopoulos et al., 2014). All cows were fed at $08 \mathrm{~h} 00$ and $14 \mathrm{~h} 00$ throughout the study. Once per sampling week at $11 \mathrm{~h} 00$, rumen fluid and biopsy samples were taken for analysis at three weeks prior to estimated parturition (PRE), one week after actual parturition (PERI) and six weeks after actual parturition (POST). Rumen fluid was collected from the ventral sac of the rumen and squeezed through 4 layers of cheesecloth and frozen at $-20^{\circ} \mathrm{C}$ for SCFA analysis (Dionissopoulos et al., 2013), principally acetate, propionate and butyrate. Rumen $\mathrm{pH}$ was spot-sampled using a portable $\mathrm{pH}$ meter (pH310, Oakton Instruments, Vernon Hills, IL).

For rumen biopsies, the rumen was partly evacuated to gain access to the ventral sac of the rumen. Approximately $150 \mathrm{mg}$ of rumen papillae were harvested, rinsed with PBS and stored in $4 \%$ formalin for $24 \mathrm{~h}$, after which papillae were processed and embedded in paraffin wax (Animal Health Laboratories, University of Guelph, Guelph, ON, Canada) for immunofluorescence analysis.

\section{Immunofluorescence}

Protein abundance of MCT1, NHE3, NBC1 and CA2 were analyzed as described previously (Laarman et al., 
2013). Longitudinal sections of rumen papillae, $5 \mu \mathrm{m}$ in thickness, were mounted on charged microscope slides (Fisher Sci, Burlington, CA). After deparaffinisation, antigens were retrieved using a $10 \mathrm{mM}$ sodium citrate buffer at $95^{\circ} \mathrm{C}$ for $30 \mathrm{~min}$, then blocked and permeabilized using $10 \%$ goat serum and $0.3 \%$ TritonX100 blocking buffer. Samples were then incubated with a rabbit polyclonal primary antibody and a goat antirabbit fluorescent secondary antibody (Fisher Sciences, Burlington, CA). After each antibody incubation, samples were rinsed three times with PBS. Slides were mounted with ProLong AntiFade reagent that included DAPI nuclear stains (Life Sciences, Burlington, ON, Canada). One negative control free of primary antibody was included for each protein analyzed.

Samples were then visualized under a TCS SP5 confocal fluorescent microscope (Leica Microsystems, Mannheim, Germany). Smart gain and Offset settings were adjusted for each protein so that the range in signal strength of the samples was matched to the range in detection of the microscope. As a result, saturated pixels were minimal in all images. Signals were then quantified in Image J (NIH, Bathesda, MD, USA) using previously established formulas adapted for use in ruminal epithelia (Gavet and Pines, 2010; Laarman et al., 2013).

\section{Statistics}

Data were analyzed using PROC MIXED in SAS 9.2 (SAS Institute), using the statistical model:

$$
\mathrm{Y}=\mu+\mathrm{T}_{\mathrm{i}}+\varepsilon_{\mathrm{ij}}
$$

Where:

$\mathrm{Y}=$ Dependant variable

$\mu=$ Variable mean

$\mathrm{T}_{\mathrm{i}}=$ Effect of time

$\varepsilon_{\mathrm{ij}}=$ Residual error

Cow was used as a repeated measure with 5 variance/covariance structures. The variance/covariance structure with the lowest Bayesian Information Criteria was used for results. Orthogonal contrasts were done on PRE Vs. PERI, PRE Vs POST and PERI Vs POST. Correlations between rumen $\mathrm{pH}$, SCFA measurements and protein abundance were done using PROC CORR.

\section{Results}

\section{Rumen SCFA Profile and Rumen pH}

Total SCFA concentrations did not change significantly over time (Dionissopoulos et al., 2014). Acetate concentrations also did not change between 3 weeks preparturition, 1 week post-parturition and 6 weeks post-parturition, measuring 40.75 \pm 1.32 , $40.53 \pm 1.32$ and $43.20 \pm 1.32 \mathrm{mM}(\mathrm{p}=0.91$, PRE v PERI; $\mathrm{p}=0.24$, PRE $\mathrm{v}$ POST; $\mathrm{p}=0.20$, PERI $\mathrm{v}$ POST;
Dionissopoulos et al., 2014). Propionate increased during the parturition period, from $17.57 \pm 1.25 \mathrm{mM}$ at PRE to $22.94 \pm 1.25 \mathrm{mM}$ at PERI and $22.26 \pm 1.25 \mathrm{mM}$ at POST $(\mathrm{p}<0.01, \mathrm{p}<0.01, \mathrm{p}=0.643$; Dionissopoulos et al., 2014). Similarly, butyrate concentrations increased over time, going from $6.97 \pm 0.52 \mathrm{mM}$ at PRE to $9.85 \pm 0.52$ $\mathrm{mM}$ at PERI and $9.40 \pm 0.52 \mathrm{mM}$ at POST $(\mathrm{p}<0.01$, $\mathrm{p}<0.01, \mathrm{p}=0.51$; Dionissopoulos et al., 2014). Mean rumen $\mathrm{pH}$ decreased over the parturition period, dropping from $6.38 \pm 0.08$ at PRE, to $5.81 \pm 0.08$ and $5.85 \pm 0.08$ at PERI and POST, respectively $(\mathrm{p}<0.01$, $\mathrm{p}<0.01, \mathrm{p}=0.73$; Dionissopoulos et al., 2014).

\section{Immunofluorescence}

From pre-parturition, through the parturition period and until 6 weeks post-parturition, there was no significant change in abundance in MCT1 protein, measuring $16878 \pm 1555$ A.U., $15613 \pm 1508$ A.U. and $16886 \pm 1555$ A.U., chronologically $(\mathrm{p}=0.64, \mathrm{p}=1.00$ and $p=0.64$, respectively; Fig. 1 and 2). Abundance of NHE3 protein also was unaffected by the parturition period. Although there was a numerical decrease in protein abundance from PRE $(10467 \pm 1066$ A.U.), to PERI (9465 \pm 1066 A.U.) and POST (8552 \pm 1109 A.U.), none of the differences were significant $(p=0.57, p=$ $0.20, p=0.61$; Fig. 3). Further, NBC1 abundance did not differ significantly in chronological sequence from 3 weeks prior to parturition to 6 weeks post-parturition $(16467 \pm 1274$ A.U., $13983 \pm 1318$ A.U., $15047 \pm 1324$ A.U.; $p=0.26, p=0.42, p=0.63$; Fig. 4). Lastly, CA2 abundance did change over time, decreasing from $12332 \pm 1580$ A.U. PRE to $7235 \pm 1580$ A.U. at PERI and $8121 \pm 1643$ A.U. at POST $(p=0.01, p=0.06, p=0.64$; Fig. 5). Abundance of NHE3 was positively correlated to rumen $\mathrm{pH}(r=0.39, \mathrm{p}=0.03$; Fig. 6) and negatively correlated to acetate concentration $(r=-0.44, \mathrm{p}=0.02)$, propionate concentration $(r=-0.55, \mathrm{p}<0.01)$ and butyrate concentration $(r=-0.55, \mathrm{p}<0.01)$.

\section{Discussion}

The purpose of this experiment was to investigate changes in transport protein abundance during the parturition period. The parturition transition period is marked by a rapid onset of negative energy balance due to energetic demands of milk production (Drackley, 1999) resulting in a mobilization of energy reserves. In the rumen, early lactation TMRs contain considerably higher NFC than dry-off TMRs, making the diet more rapidly fermentable. Approximately $50 \%$ of ruminallyproduced SCFAs are translocated across the rumen epithelium (Allen, 1997), thus the rumen epithelium's adaptation during the parturition transition warrant further investigation. How a more rapidly fermentable diet combined with increased energy demands affects the transport capacity of the rumen epithelium is unclear. 


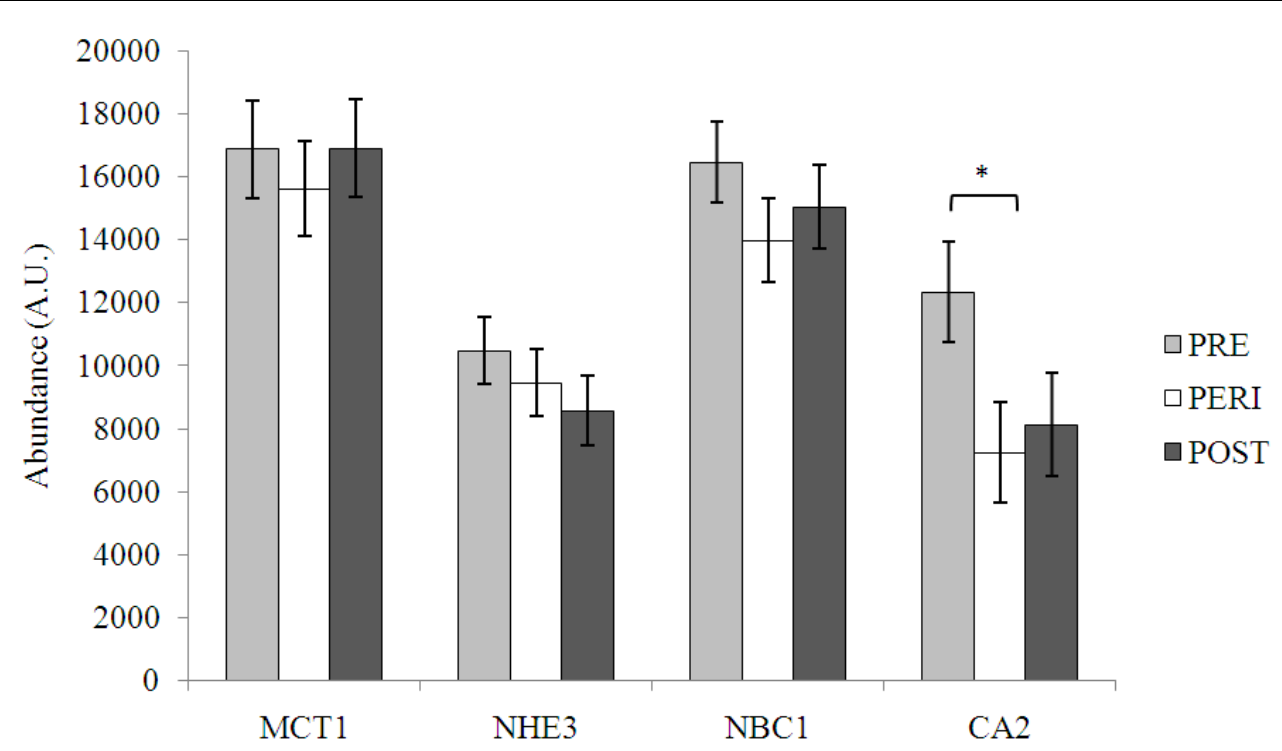

Fig. 1. Protein abundance of membrane transport proteins in the rumen epithelium of Holstein dairy cows during the periparturient transition ( $\mathrm{PRE}=3$ weeks prior to planned parturition; PERI $=1$ week after parturition; POST $=6$ weeks after parturition) *Significantly different from PRE $(\mathrm{p}<0.05)$

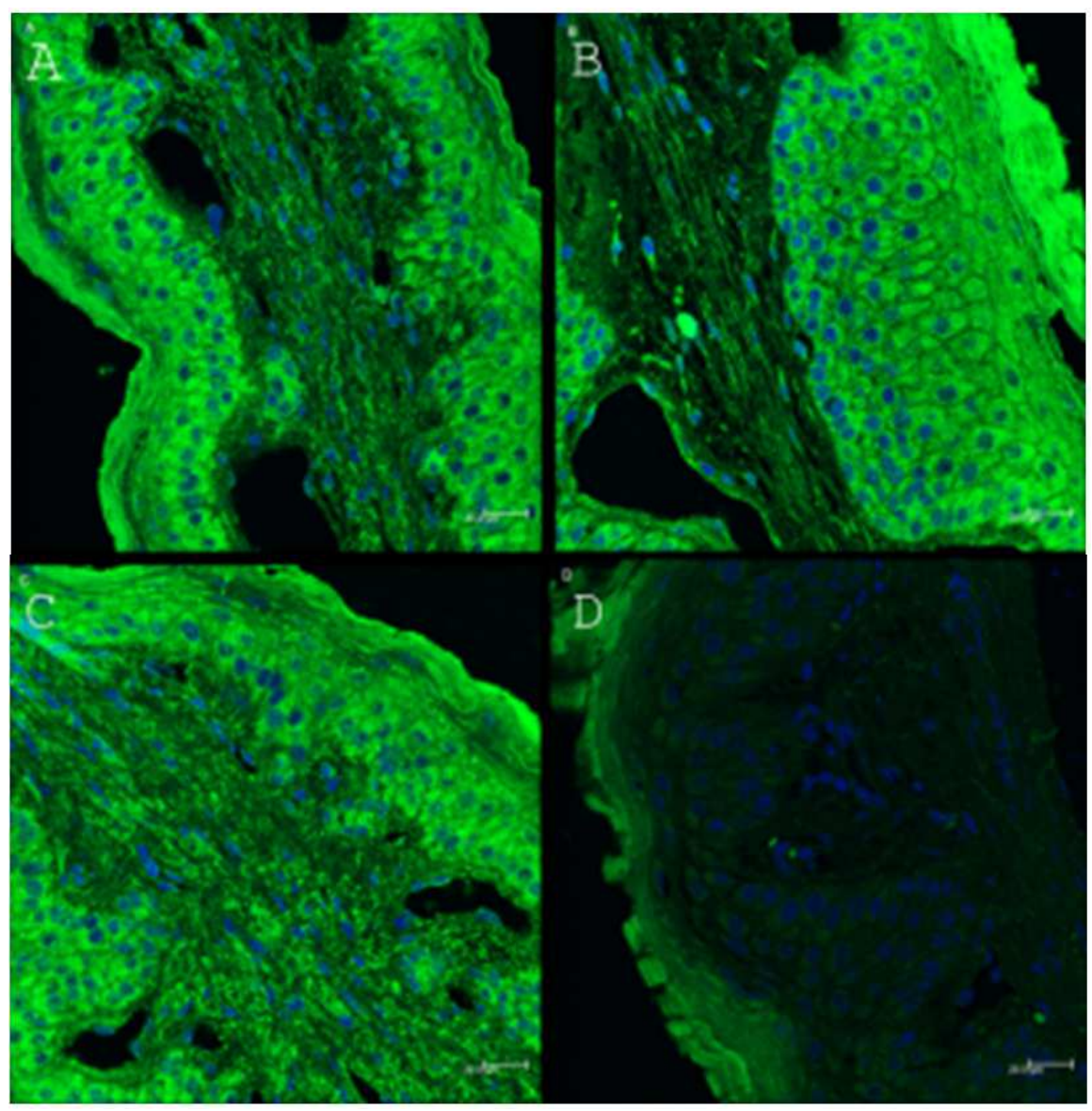

Fig. 2. Abundance of MCT1 in rumen epithelium of Holstein dairy cows during the periparturient period. $A=P R E$ ( 3 weeks prior to parturition), B = PERI (1 week after parturition), $\mathrm{C}=$ POST (6 weeks after parturition), $\mathrm{D}=$ Negative control (secondary antibody only); scale bar $=20.0 \mu \mathrm{m}$ 


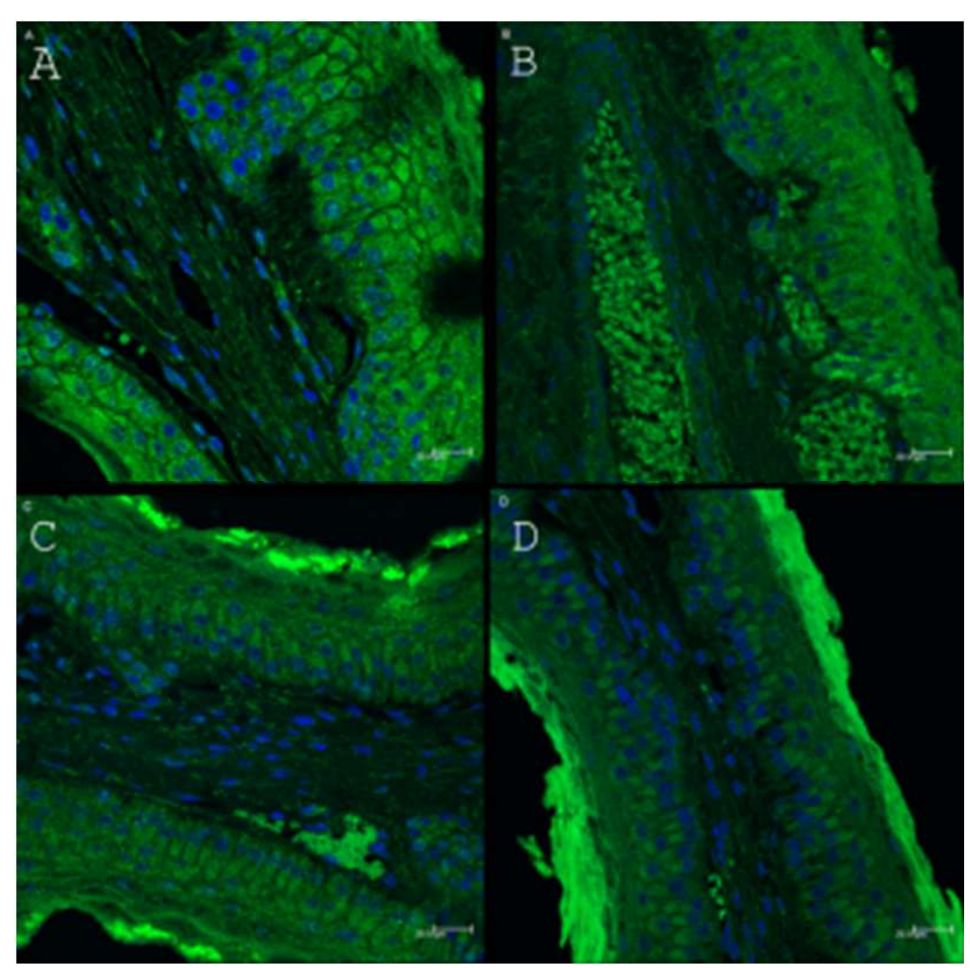

Fig. 3. Abundance of NHE3 in rumen epithelium of Holstein dairy cows during the periparturient period. A $=$ PRE ( 3 weeks prior to parturition), B = PERI (1 week after parturition), C = POST (6 weeks after parturition), D = Negative control (secondary antibody only); scale bar $=20.0 \mu \mathrm{m}$

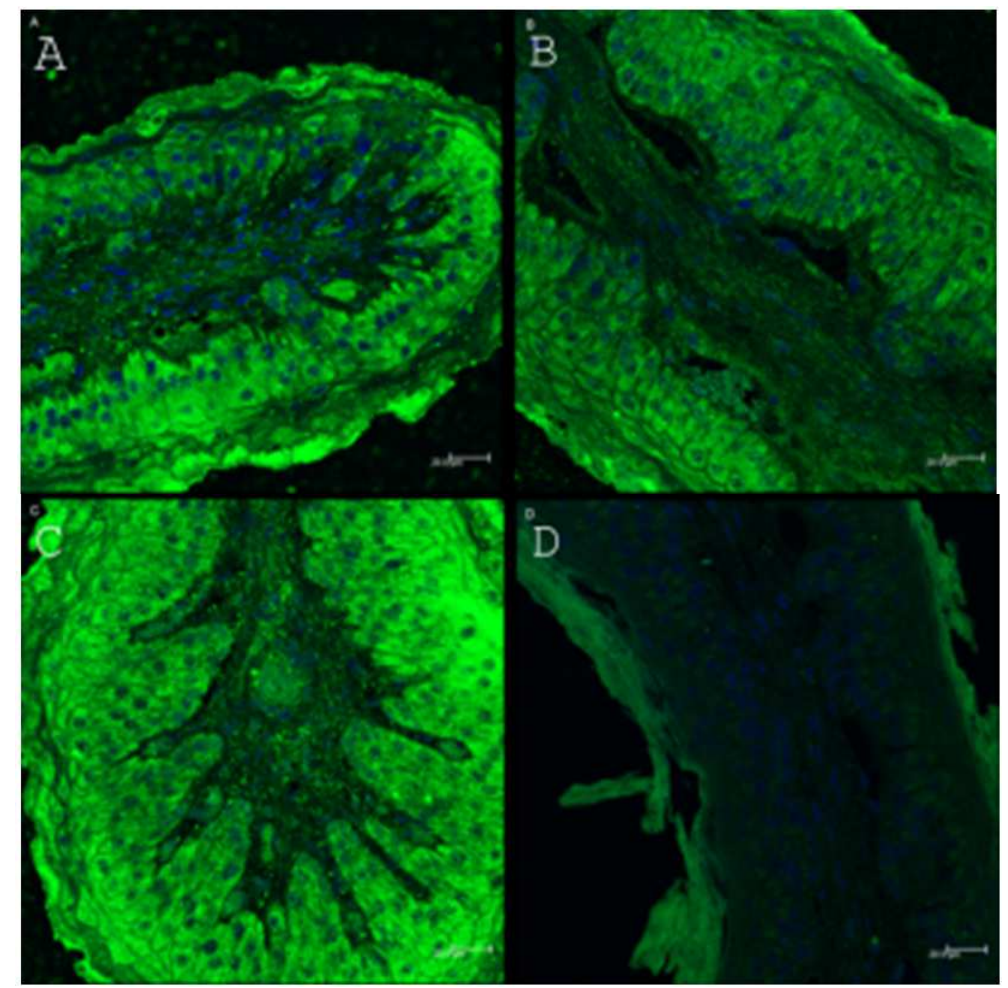

Fig. 4. Abundance of $\mathrm{NBC} 1$ in rumen epithelium of Holstein dairy cows during the periparturient period. $\mathrm{A}=\mathrm{PRE}$ ( 3 weeks prior to parturition), $\mathrm{B}=$ PERI (1 week after parturition), $\mathrm{C}=$ POST (6 weeks after parturition), $\mathrm{D}=$ Negative control (secondary antibody only); scale bar $=20.0 \mu \mathrm{m}$ 


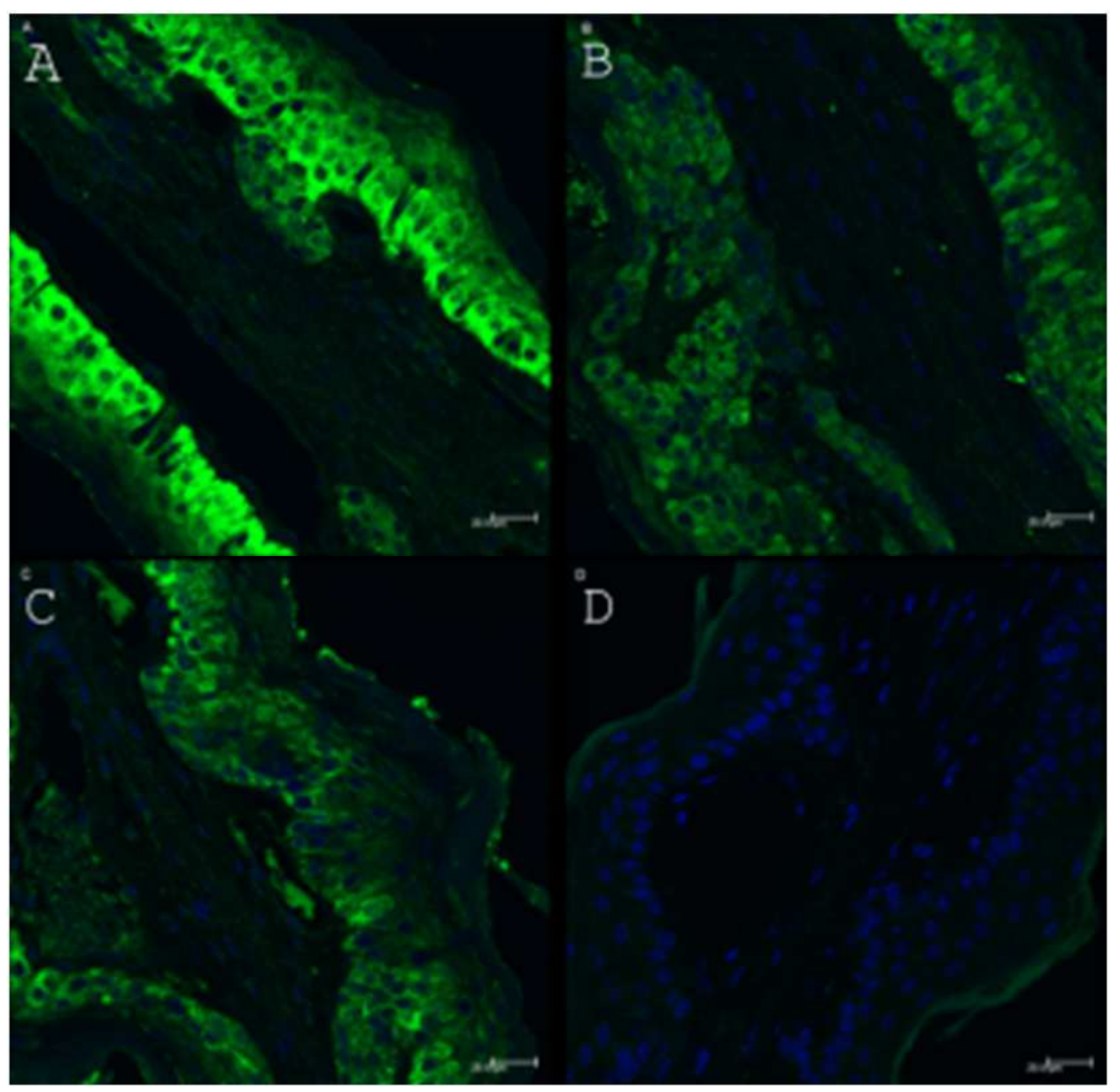

Fig. 5. Abundance of CA2 in rumen epithelium of Holstein dairy cows during the periparturient period. $A=P R E$ ( 3 weeks prior to parturition), B = PERI (1 week after parturition), $\mathrm{C}=$ POST (6 weeks after parturition), D = Negative control (secondary antibody only); scale bar $=20.0 \mu \mathrm{m}$

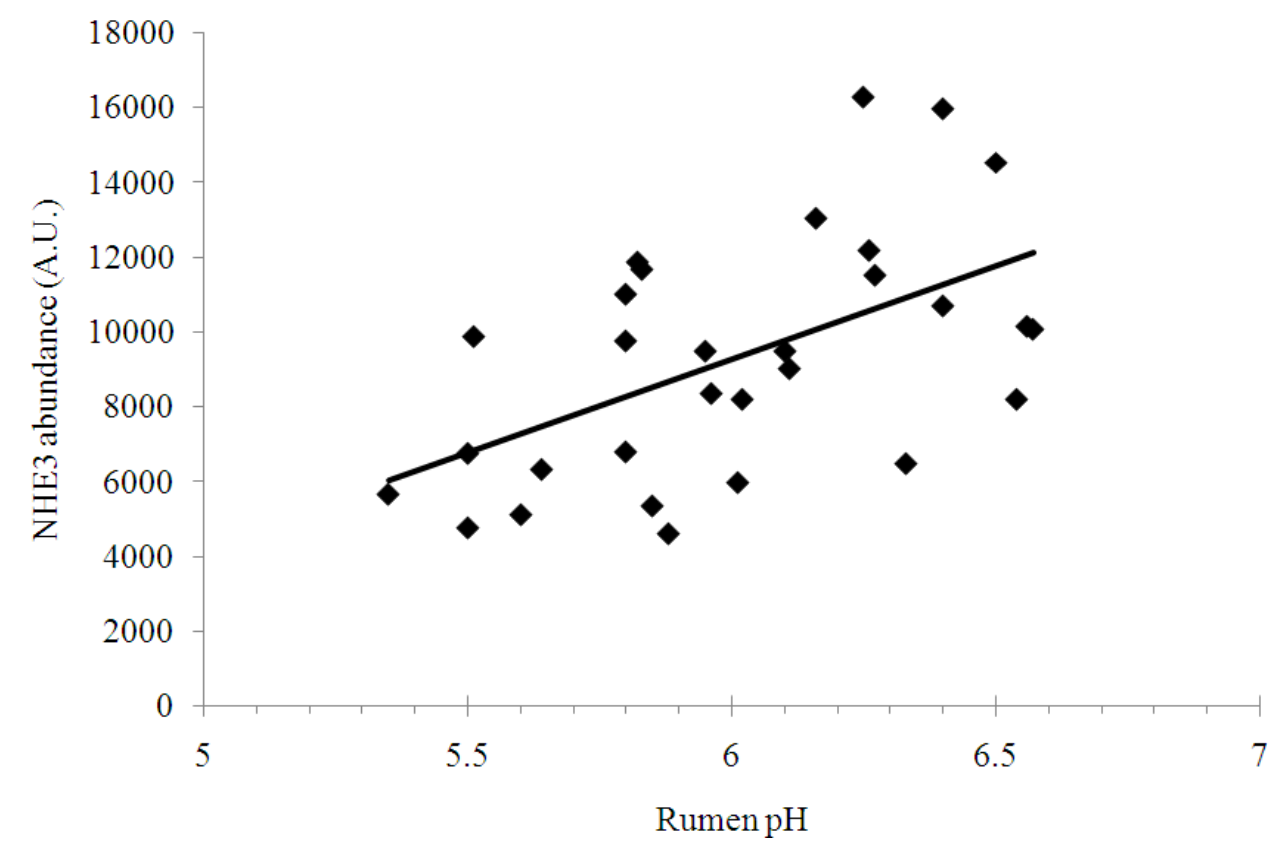

Fig. 6. Relationship between rumen $\mathrm{pH}$ and the abundance of NHE3 proteins in the rumen epithelium $(\mathrm{r}=0.39, \mathrm{p}=0.03)$ 


\section{Transport Capacity}

Moving SCFA across the ruminal epithelium is determined by several factors. While passive diffusion across the rumen epithelium certainly occurs, proteinmediated transport is also an important mechanism by which SCFA are transported from the lumen into the bloodstream (Aschenbach et al., 2009). During the periparturient period, both rumen $\mathrm{pH}$ and epithelial carbonic anhydrase 2 decreased. Carbonic anhydrase bidirectionally catalyzes the reaction between bicarbonate and carbon dioxide, associating with bicarbonate transporters such as AE1 and NBC1 to increase bicarbonate transport (Purkerson and Schwartz, 2007). The presence of CA2 increases MCT1 transport activity (Klier et al., 2014), which makes the decreased CA2 expression in our study puzzling from a transport capacity perspective.

In addition, the lack of response of MCT1 and NHE3 to changes in pregnancy is somewhat surprising, but may be due to morphological changes in rumen papillae that occur concurrently. In goats fed $90 \mathrm{~g}$ of concentrate per kilo of metabolic body weight, rumen papillae were significantly longer and wider, with a resulting increase in surface area, than goats fed only $20 \mathrm{~g}$ of concentrate per kilo of metabolic weight (Shen et al., 2004). In cows, the parturition transition is characterized with welldocumented increases in rumen papillae surface area (Martens et al., 2012); these changes in papillae size were visually confirmed in our study. The most likely explanation for our findings, in light of past studies, is that the morphological changes in the rumen are the main drivers of increases in transport capacity. That is to say that the same transport protein abundance per cell over the time period is still resulting in increased transport capacity because the number of cells increased drastically over the course of our study. In sheep, a transition from a hay diet to a mixed hay/concentrate diet, similar to dairy cow periparturient transition, results in a marked increase in mucosal to serosal sodium flux in the first week post-transition and this increase is sustained for 12 weeks (Etschmann et al., 2009). Taken together, this likely means that transport-protein-mediated adaptation in the rumen likely takes place in the first week following dietary changes. Gene expression changes associated with a switch from a high forage diet to a high concentrate diet occurred primarily in the first weeks after the dietary change (Steele et al., 2011), so the first several weeks following diet transition is most important in adaptations in cellular transport capacity.

\section{Epithelial Remodelling}

Epithelial remodelling may be the principal route for long-term changes in transport capacity. In the rumen epithelium, expression of genes involved in epithelial remodelling is modulated within one week of exposure to subacute ruminal acidosis (Dionissopoulos et al., 2013), so epithelial remodelling begins rather quickly after a dietary change. Recently, Schurmann et al. (2014) found part of the adaptive process in the rumen epithelium is an increase in passive diffusion and in the size of large papillae in the first 21 days of adaptation from a high forage diet to a moderately fermentable diet. The increase in passive diffusion is likely due to epithelial integrity disruption, pointing to evidence of epithelial remodelling, which is corroborated by the increase in papillae size in that study.

During epithelial remodelling, one of the first and important steps is the promotion of cell migration, which involves the cleaving of anchoring extracellular matrix proteins (Streuli, 1999). One of the ways the extracellular matrix proteins can be modulated is through intracellular acidification. Intracellular acidification disrupts the Connexin43/Zonal-Occludens 1 interactions in cardiac myocytes and results in reduced intercellular coupling, promoting remodelling of junctions (Duffy et al., 2004).

In our study, the decreased abundance of $\mathrm{CA} 2$ in the PERI and POST and the positive correlation of NHE3 abundance to rumen $\mathrm{pH}$ could actually be related to epithelial remodelling by causing intracellular acidification of the epithelium. Decreased CA2 abundance results in less elimination of protons from the cytosol through the $\mathrm{HCO}_{3} / \mathrm{CO}_{2}$ equilibrium, while a lower NHE3 abundance means fewer protons are being expelled from the epithelial cell cytosol into the rumen. After parturition, when acetate, propionate and butyrate concentrations increase and ruminal $\mathrm{pH}$ drops, as was the case in our study, the increased proton influx from the rumen would presumably result in intracellular acidification in an environment with less CA2 and less NHE3 because fewer protons are being removed from the cytosol through CA2 catalysis and NHE3 efflux. From this perspective, the results in this study indicate that intracellular acidification might be occurring as part of the remodelling of the epithelium in the periparturient transition period.

\section{Conclusion}

During the parturition transition, morphological changes in the rumen wall were not accompanied by changes in the abundance of MCT1, NHE3 and NBC1. Protein abundance of CA2 decreased during the PERI and POST periods, suggesting that intracellular acidification may be occurring as fewer protons are being converted into $\mathrm{CO}_{2}$ and $\mathrm{H}_{2} \mathrm{O}$. More evidence of intracellular acidification came from the positive correlation between NHE3 abundance and rumen $\mathrm{pH}$. As rumen $\mathrm{pH}$ decreased, proton expulsion from the epithelial cell cytosol was decreased, furthering intracellular acidotic pressure. Intracellular acidification aids in breaking down cell adhesion to extracellular matrix components and thus contributes to epithelial remodelling in the periparturient transition. 
Future research could focus on the role of epithelial remodelling in optimizing transport capacity of SCFAs during major dietary transitions, to balance disease risk with the need for changes in transport capacity across the rumen epithelium. Changes in the rumen epithelium affects both disease risk as well as transport capacity of SCFAs and an effective balance between the two must be pursued for optimal health and productivity of dairy cows during the periparturient transition period.

\section{Acknowledgement}

The authors would like to acknowledge funding from the Natural Sciences and Engineering Research Council and a scholarship from the Ontario Ministry of Agriculture and Food. Also, we would like to thank the staff at the Elora Dairy Research Station of the University of Guelph for their technical assistance. Lastly, the authors acknowledge the Molecular and Cellular Imaging Facility at the Advanced Analysis Centre, University of Guelph, for the use of the confocal laser microscope.

\section{Funding Information}

The study was funded by the Natural Sciences and Engineering Council.

\section{Author's Contributions}

Anne Hermen Laarman: Contributed to the planning and execution of the study, the laboratory and statistical analysis and the writing of the manuscript.

Adam Kleinberg: Contributed to the execution of the study and editing of the manuscript.

Michael Alexander Steele and Ousama AlZahal: Contributed to the planning and execution of the study and the editing of the manuscript.

Brian William McBride: The principal investigator of the study.

\section{Ethics}

The authors have no conflict of interest. This study was carried out with the approval of the Animal Care Committee at the University of Guelph, under the guidelines of the Canadian Council for Animal Care.

\section{References}

Allen, M.S., 1997. Relationship between fermentation acid production in the rumen and the requirement for physically effective fiber. J. Dairy Sci., 80: 1447-1462.

DOI: $10.3168 /$ jds.S0022-0302(97)76074-0
AlZahal, O., B. Rustomo, N.E. Odongo, T.F. Duffield and B.W. McBride, 2007. Technical note: A system for continuous recording of ruminal $\mathrm{pH}$ in cattle. $\mathrm{J}$. Anim. Sci., 85: 213-217. PMID: 17179558

Aschenbach, J.R., S. Bilk, G. Tadesse, F. Stumpff and G. Gäbel, 2009. Bicarbonate-dependent and bicarbonate-independent mechanisms contribute to nondiffusive uptake of acetate in the ruminal epithelium of sheep. Am. J. Physiol. Gastr. Liver Physiol., 296: G1098-G1107. DOI: 10.1152/ajpgi.90442.2008

Connor, E.E., R.W. Li, R.L. Baldwin and C. Li, 2010. Gene expression in the digestive tissues of ruminants and their relationships with feeding and digestive processes. Animal, 4: 993-1007. DOI: $10.1017 / \mathrm{S} 1751731109991285$

Dionissopoulos, L., A.H. Laarman, O. AlZahal, S.L. Greenwood and M.A. Steele et al., 2013. Butyratemediated genomic changes involved in non-specific host defenses, matrix remodeling and the immune response in the rumen epithelium of cows afflicted with subacute ruminal acidosis. Am. J. Anim. Vet. Sci., 8: 8-27. DOI: 10.3844/ajavsp.2013.8.27

Dionissopoulos, L., O. AlZahal, M.A. Steele, J.C. Matthews and B.W. McBride, 2014. Transcriptomic changes in ruminal tissue induced by the periparturient transition in dairy cows. Am. J. Anim. Vet. Sci., 9: 36-45. DOI: 10.3844/ajavsp.2014.36.45

Drackley, J.K., 1999. ADSA foundation scholar award. Biology of dairy cows during the transition period: The final frontier? J. Dairy Sci., 82: 2259-2273. PMID: 10575597

Duffy, H.S., A.W. Ashton, P. O'Donnell, W. Coombs and S.M. Taffet et al., 2004. Regulation of connexin43 protein complexes by intracellular acidification. Circulation Res., 94: 215-222. DOI: 10.1161/01.res.0000113924.06926.11

Etschmann, B., A. Suplie and H. Martens, 2009. Change of ruminal sodium transport in sheep during dietary adaptation. Archives Anim. Nutr., 63: 26-38. DOI: $10.1080 / 17450390802506885$

Gavet, O. and J. Pines, 2010. Progressive activation of CyclinB1-CDK1 coordinates entry to mitosis. Dev. Cell, 18: 533-543.

DOI: $10.1016 /$ j.devcel.2010.02.013

Graham, C. and N.L. Simmons, 2005. Functional organization of the bovine rumen epithelium. Am. J. Physiol. Regul. Integr. Comp. Physiol., 288: R173-R181. DOI: 10.1152/ajpregu.00425.2004

Graham, C., I. Gatherar, I. Haslam, M. Glanville and N.L. Simmons, 2007. Expression and localization of monocarboxylate transporters and sodium/proton exchangers in bovine rumen epithelium. Am. J. Physiol. Regul. Integr. Comp. Physiol., 292: R997-R1007. DOI: 10.1152/ajpregu.00343.2006 
Kiela, P.R., J. LeSueur, J.F. Collins and F.K. Ghishan, 2003. Transcriptional regulation of the rat NHE3 gene functional interactions between GATA-5 and Sp family transcription factors. J. Biol. Chem., 278: 5659-5668. DOI: 10.1074/jbc.M209473200

Klier, M., F.T. Andes, J.W. Deitmer and H.M. Becker, 2014. Intracellular and extracellular carbonic anhydrases cooperate non-enzymatically to enhance activity of monocarboxylate transporters. J. Biolog. Chem., 289: 2765-2775. DOI: $10.1074 /$ jbc.M113.537043

Laarman, A.H., L. Dionissopoulos, O. AlZahal, S.L. Greenwood and M.A. Steele et al., 2013. Butyrate and subacute ruminal acidosis affect abundance of membrane proteins involved with proton and short chain fatty acid transport in the rumen epithelium of dairy cows. Am. J. Anim. Vet. Sci., 8: 220-229. DOI: 10.3844/ajavsp.2013.220.229

Martens, H., I. Rabbani, Z. Shen, F. Stumpff and C. Deiner, 2012. Changes in rumen absorption processes during transition. Animal Feed Sci. Technol., 172: 95-102.

DOI: $10.1016 /$ j.anifeedsci.2011.12.011

Muller, F., J.R. Aschenbach and G. Gäbel, 2000. Role of $\mathrm{Na}^{+} / \mathrm{H}^{+}$exchange and $\mathrm{HCO}_{3}^{-}$transport in $\mathrm{pH}_{\mathrm{i}}$ recovery from intracellular acid load in cultured epithelial cells of sheep rumen. J. Comp. Physiol. B, 170: 337-343. DOI: $10.1007 / \mathrm{s} 003600000107$

Plaizier, J.C., D.O. Krause, G.N. Gozho and B.W. McBride, 2008. Subacute ruminal acidosis in dairy cows: The physiological causes, incidence and consequences. Vet. J., 176: 21-31. DOI: $10.1016 /$ j.tvj1.2007.12.016

Purkerson, J.M. and G.J. Schwartz, 2007. The role of carbonic anhydrases in renal physiology. Kidney Int., 71: 103-115. DOI: 10.1038/sj.ki.5002020
Reynolds, C.K., B. Durst, B. Lupoli, D.J. Humphries and D.E. Beever, 2004.Visceral tissue mass and rumen volume in dairy cows during the transition from late gestation to early lactation. J. Dairy Sci., 87: 961-971. DOI: $10.3168 /$ jds.S0022-0302(04)73240-3

Schurmann, B.L., M.E. Walpole, P. Górka, J.C. Ching and M.E. Loewen et al., 2014. Short-term adaptation of the ruminal epithelium involves abrupt changes in sodium and short-chain fatty acid transport. Am. J. Physiol. Regul. Integr. Comp. Physiol. DOI: 10.1152/ajpregu.00035.2014

Shen, Z., H.M. Seyfert, B. Löhrke, F. Schneider and R. Zitnan et al., 2004. An energy-rich diet causes rumen papillae proliferation associated with more IGF type 1 receptors and increased plasma IGF-1 concentrations in young goats. J. Nutr., 134: 11-17. PMID: 14704286

Steele, M.A., G. Vandervoort, O. AlZahal, S.E. Hook and J.C. Matthews et al., 2011. Rumen epithelial adaptation to high-grain diets involves the coordinated regulation of genes involved in cholesterol homeostasis. Physiol. Genomics, 43: 308-316.

DOI: 10.1152 /physiolgenomics.00117.2010

Sterling, D., R.A. Reithmeier and J.R. Casey, 2001. A transport metabolon. Functional interaction of carbonic anhydrase II and chloride/bicarbonate exchangers. J. Biol. Chem., 276: 47886-47894. PMID: 11606574

Streuli, C., 1999. Extracellular matrix remodelling and cellular differentiation. Curr. Opin. Cell Biol., 11: 634-640. DOI: 10.1016/S0955-0674(99)00026-5 